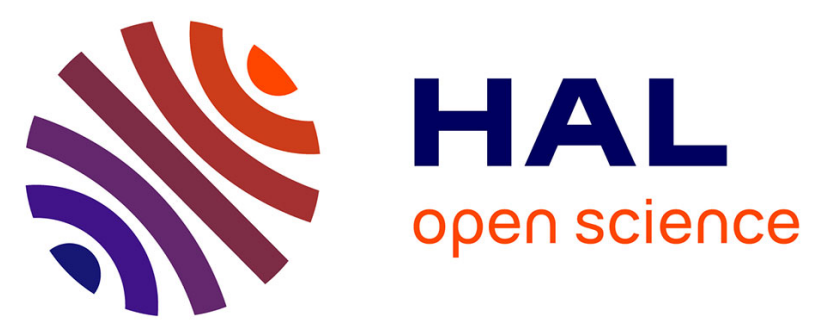

\title{
How to reduce the duration of multiaxial fatigue tests under proportional service loadings
}

Thierry Palin-Luc, Alexis Banvillet, Jean-François Vittori

\section{To cite this version:}

Thierry Palin-Luc, Alexis Banvillet, Jean-François Vittori. How to reduce the duration of multiaxial fatigue tests under proportional service loadings. International Journal of Fatigue, 2006, Selected papers from the 7th International Conference on Biaxial/Multiaxial Fatigue and Fracture (ICBMFF), 7th International Conference on Biaxial/Multiaxial Fatigue and Fracture, 28 (5-6), pp.554563. 10.1016/j.ijfatigue.2005.07.041 . hal-01373462

\section{HAL Id: hal-01373462 https://hal.science/hal-01373462}

Submitted on 28 Sep 2016

HAL is a multi-disciplinary open access archive for the deposit and dissemination of scientific research documents, whether they are published or not. The documents may come from teaching and research institutions in France or abroad, or from public or private research centers.
L'archive ouverte pluridisciplinaire HAL, est destinée au dépôt et à la diffusion de documents scientifiques de niveau recherche, publiés ou non, émanant des établissements d'enseignement et de recherche français ou étrangers, des laboratoires publics ou privés. 


\title{
How to reduce the duration of multiaxial fatigue tests under proportional service loadings
}

\author{
Thierry Palin-Luc $^{\mathrm{a}, *}$, Alexis Banvillet ${ }^{\mathrm{b}, 1}$, Jean-François Vittori ${ }^{\mathrm{c}}$ \\ ${ }^{a}$ ENSAM CER de Bordeaux, Laboratoire Matériaux Endommagement Fiabilité et Ingénierie des Procédés (LAMEFIP), EA 2727, \\ Esplanade des Arts et Métiers, F-33405 Talence Cedex, France \\ ${ }^{\mathrm{b}}$ CEA-CESTA, 15 Av. des Sablières, B.P. 2, F-33114 Le Barp, France \\ ${ }^{\mathrm{c}}$ RENAULT, Technocentre, Dir. Ingénierie des Matériaux, 1 Av. Golf, F-78288 Guyancourt, France
}

\begin{abstract}
This paper deals with a technique to transform a multiaxial stress and strain-time sequence (in service recorded) in a simplified sequence. This simplified sequence is shorter than the original one and equivalent in terms of damage and lifetime: the number of simplified sequences to crack initiation is equal to the number of original sequences. The proposal is based on an energy threshold, below which no micro-crack can initiate or grow in the material. This technique was validated with real loading sequences recorded by strain gauges pasted on a car suspension arm. Fatigue tests were carried out on smooth specimens made of spheroidal graphite cast iron loaded in bending, in torsion and in combined bending and torsion. Experimental fatigue lives under the original sequence and under the simplified one are in very good correlation. Fatigue test duration is reduced up to a factor of 10 for the severe stress-strain sequences tested in this study.
\end{abstract}

Keywords: Multiaxial fatigue; Accelerated fatigue test; Load sequence; Energy; Threshold; Variable amplitude

\section{Introduction}

To validate the design of a safety component, multiaxial fatigue tests under service loads (variable amplitude) have to be carried out. Such tests are very often long; that is one of the reasons why engineers need some tools to reduce their duration. Some techniques based on rainflow cycle counting methods, small cycles filtering and load reconstruction already exist in the literature [1-3]. Even if these methods give good results for uniaxial loading, no technique is today accepted by everybody for being used efficiently under multiaxial loading. This paper presents a technique to transform a real proportional multiaxial stress strain time sequence (recorded in-service from strain gauges stuck on a component) in a simplified one which is shorter in time

\footnotetext{
* Corresponding author. Tel./fax: +33556845360.

E-mail address: thierry.palin-luc@lamef.bordeaux.ensam.fr (T. PalinLuc).

${ }^{1} \mathrm{PhD}$ student at ENSAM - LAMEFIP during this work - Now Dr. at CEA CESTA.
}

0142-1123 than the original one and equivalent in term of fatigue life: the number of simplified sequences to fatigue crack initiation is the same as the number of original sequences. The proposal is based on the non-damaging threshold stress proposed by Palin-Luc et al. [4-7] and its equivalent strain work density given to an elementary volume of material between a peak and a valley of the stress history. These concepts are summarized first hereafter; secondly, the technique to simplify an original sequence is presented. Finally, a comparison between fatigue tests in real time and tests using the simplified sequences is shown before discussing the advantages and drawbacks of the proposal.

\section{Accelerated testing technique}

The aim of this paper is to present a technique to suppress in a multiaxial stress strain time history the non-damaging part $[8,9]$. A shortest stress strain time history is thus obtained, but the proposed technique does not deal with the reduction of the loading histories. The authors consider that with regard to the material, the damaging signals are not the loadings, but the 


\author{
Nomenclature \\ $\mathrm{d} T(M)$ triaxiality degree of stresses at point $M$ \\ $t \quad$ time \\ $C_{\mathrm{i}} \quad$ fatigue critical point \\ $E \quad$ Young modulus \\ $F(\mathrm{~d} T, \beta)$ correction function depending on the triaxiality \\ degree of stresses \\ $K t_{\text {bend }}$ theoretical stress concentration factor in bending \\ $K t_{\text {tor }}$ theoretical stress concentration factor in torsion \\ $N f_{0.50} \quad$ number of sequences to fatigue crack initiation for \\ the probability of 0.50 \\ $N f_{x} \quad$ number of sequences to fatigue crack initiation for \\ the probability of $x$ \\ $T \quad$ loading period for cylcic loading \\ $V^{*} \quad$ volume influencing fatigue crack initiation \\ $\mathrm{Wg}$ strain work density given to the material on a \\ loading period
}

$\mathrm{Wg} * \quad$ threshold value of $\mathrm{Wg}$ corresponding to $\sigma^{*}$

$\beta \quad$ material parameter characteristic of the material sensitivity to the triaxiality of stresses

$\varepsilon_{\mathrm{ij}}(M, t)$ strain tensor at point $M$, function of time

$\nu \quad$ Poisson ratio

$\xi_{\mathrm{i}} \quad$ signed potential strain energy density corresponding to $\sigma_{\mathrm{i}}$ and $\varepsilon_{\mathrm{i}}$

$\sigma_{\mathrm{ij}}(M, t)$ stress tensor at point $M$, function of time

$\sigma^{*} \quad$ threshold stress below which there is no micro damage initiation

$\sigma_{\text {ten,-1 }}^{D} \quad$ fully reversed endurance limit in tension on smooth specimen

$\sigma_{\text {rotben,-1 }}^{D}$ fully reversed endurance limit in rotating bending on smooth specimen

$\tau_{\mathrm{to},-1}^{D} \quad$ fully reversed endurance limit in torsion on smooth specimen stress and strain signals caused by the loadings, the component geometry and the material behaviour. To validate a component, the designer has to localize the critical areas or points $\left(C_{\mathrm{i}}\right)$ with regard to fatigue crack initiation. Then, from the transfert function $^{2}$ of the test rig (where the component will be tested), the multiaxial loading-time history has to be computed in order to reproduce the stress and strain-time history as recorded in service at the critical points $C_{\mathrm{i}}$ (on a prototype for instance). In all this paper, the design of the component is supposed to be done so that the material remains elastic at the macroscopic scale (even if there is some local plasticity at the mesoscopic scale). An elastic shakedown state is supposed to occur in order to reach high cycle fatigue [10,5]. The component is supposed not to be loaded so that there are macroscopic plastic strains leading to low cycle fatigue.

\subsection{Non-damaging threshold}

Based on fully reversed plane bending fatigue tests (with stress amplitude varying in blocks) on smooth specimens made of a spheroidal graphite cast iron, Palin-Luc et al. [4] proves that blocks with stress amplitude below the conventional endurance limit $\sigma^{D}$, and above a threshold stress amplitude called $\sigma^{*}$, participate in damage. If the stress amplitude is lower than $\sigma^{*}$, the fatigue life is not reduced significantly. SEM observations showed that a stress amplitude below $\sigma^{*}$ does not initiate observable damage at the microscale (no micro-crack). But, cycles with a stress amplitude between $\sigma^{*}$ and $\sigma^{D}$ contribute to damage propagation if some cycles with stress amplitude higher than $\sigma^{D}$ are previously applied. These observations were confirmed by fully reversed torsion fatigue

\footnotetext{
${ }^{2}$ The transfert function of the test rig is the mathematical relation between the driving signal of an actuator of the test rig and the stress or strain signal applied on a component at the critical point.
}

tests in blocks on the same cast iron [11]. Recently, Delahay [12] showed the same behaviour on a titanium alloy Ti6Al4V. This non-damaging threshold stress is the basic idea of the proposed technique to suppress the non-damaging parts from the original stress time history. For a multiaxial stress state, an energy quantity presented below is used.

\subsection{Strain work given}

Banvillet et al. [5,6] proposed for cyclic loadings a volumetric energy based multiaxial fatigue criterion, which considers the strain work density given to each elementary volume of material per loading cycle $\mathrm{Wg}$

$\mathrm{Wg}(M)=\sum_{i, j} \int_{T}\left\langle\sigma_{i j}(M, t) \dot{\varepsilon}_{i j}^{e}(M, t)\right\rangle \mathrm{d} t$

as damage parameter, where $\langle x\rangle$ is the Mac Cauley braket $(\langle x\rangle=x$ if $x>0 ;\langle x\rangle=0$ if $x \leq 0), t$ is the time, $M$ is the considered point, $\sigma_{\mathrm{ij}}$ and $\dot{\varepsilon}_{i j}^{e}$ are, respectively, the stress tensor and the elastic strain tensor after elastic shakedown which is supposed to occur in high cycle and middle cycle fatigue [10]. Wg is equal to the integral of the positive part of the strain power density over a loading cycle; this is also equal to the positive variation of the strain energy density due to each stress-strain component over a loading period $T$.

By reference to a homogeneous fully reversed uniaxial stress state, the threshold value of $\mathrm{Wg}$ corresponding to $\sigma^{*}$ is $\mathrm{Wg}_{\text {uniax }}^{*}=\left(\sigma^{*}\right)^{2} / E$, where $E$ is the Young modulus of the material. Banvillet et al. [5,6] demonstrated that their multiaxial fatigue criterion leads to Eq. (2) to estimate the threshold stress from two fully reversed endurance limits on smooth specimens in rotating bending $\sigma_{-1 \text {,rotben }}^{D}$ and tension $\sigma_{-1 \text {,ens }}^{D}$.

$\sigma^{*}=\sqrt{2\left(\sigma_{-1, \text { tens }}^{D}\right)^{2}-\left(\sigma_{-1, \text { rotben }}^{D}\right)^{2}}$ 
To take the effect of the stress triaxiality into account and to consider its influence on this threshold, Palin-Luc et al. [7] and Banvillet et al. [5,6] introduced an empirical function $F$, Eq. (3), depending on both, the triaxiality degree of stresses $\mathrm{d} T(M)=\mathrm{Wg}^{\mathrm{sph}}(M) / \mathrm{Wg}(M)$ and a material parameter $\beta$ (see $[5,6]$ for details). $\mathrm{Wg}^{\mathrm{sph}}(M)$ is the given strain work density due to the spherical part of the stress tensor [5], $\beta$ is identified from the fully reversed endurance limits in rotating bending, $\sigma_{\text {rotben,-1 }}^{D}$, and in torsion, $\tau_{\text {to, }-1}^{D}$, on smooth specimens [5]. The threshold strain work energy density for any stress state at the considered point $\mathrm{M}$ can be computed from Eq. (4) where $d T_{\text {uniax }}=(1-2 \nu) / 3 ; \nu$ is the Poisson ratio.

$F(\mathrm{~d} T(M), \beta)$

$$
=\frac{1}{1-\mathrm{d} T(M)}\left\{1-\frac{1}{\beta} \ln [1+(\exp (\beta)-1) \mathrm{d} T(M)]\right\}
$$

$W g^{*}=\frac{F(\mathrm{~d} T(M), \beta)}{F\left(\mathrm{~d} T_{\text {uniax }}, \beta\right)} W g_{\text {uniax }}^{*}$

\subsection{Energy function}

To identify, the non-damaging transitions between two extrema (peak and valley) of each $\sigma_{\mathrm{ij}}(t)$, in the real sequence, first it is necessary to compute the strain work density given to the material during each transition. To simplify equations, let us note stresses and strains with the engineering notation: $\sigma_{\mathrm{ij}}=$ $\sigma_{k}$ and $\varepsilon_{\mathrm{ij}}=\varepsilon_{\mathrm{k}}$ with $k=i$ if $i=j$ and $k=9-(i+j)$ if $i \neq j$. To distinguish tension from compression during a load cycle, the signed potential strain energy density, $\xi_{\mathrm{i}}(t)$, corresponding to the $i$ th stress-strain component, is introduced with Eq. (5), where $\operatorname{sign}(x)=1$ if $x>0$ and $\operatorname{sign}(x)=-1$ if $x<0$.

$\xi_{i}(M, t)=\frac{\sigma_{i}(M, t) \varepsilon_{i}(M, t)}{2} \operatorname{sign}\left(\sigma_{i}(M, t)\right)$

This parameter is illustrated in Fig. 1. For the cases $a$ and $b$ in this figure, the stress ratio $\left(R_{\sigma}=\sigma_{\min } / \sigma_{\max }\right)$ is negative, the potential strain energy density, $(1 / 2) \sigma(t) \varepsilon(t)$, has two positive variations during a period $T$; the sum of these two variations is equal to the range of $\xi(t)$. Fig. 1(c) and (d) illustrate two cases where $R_{\sigma}>0$ : there is only one positive variation of (1/ 2) $\sigma(t) \varepsilon(t)$. In Fig. 1(c), this is the strain work density given to the material in tension $(\xi(t)>0)$, whereas in Fig. 1(d) this is the strain work density given to the material in compression $(\xi(t)<0)$. Fig. 1(e) and (f), illustrate the case where $\sigma_{\min }=0$ (respectively, $\sigma_{\max }=0$ ); these two configurations are special cases of Fig. 1(c) and (d), respectively.

Since, all the $\sigma_{\mathrm{ij}}(t)$ and $\varepsilon_{\mathrm{ij}}(t)$ are synchronous under proportional multiaxial loading, the strain work energy density given to the material can be computed with Eq. (6).

$$
\begin{aligned}
& \mathrm{Wg}\left(M, t_{k} \rightarrow t_{k+1}\right)=\sum_{i=1}^{6} \Delta^{+}\left[\xi_{i}\left(M, t_{k}\right), \xi_{i}\left(M, t_{k+1}\right)\right] \\
& =\Delta^{+}\left[\xi\left(M, t_{k}\right), \xi\left(M, t_{k+1}\right)\right]
\end{aligned}
$$

$\Delta^{+}\left[\xi\left(M, t_{k}\right), \xi\left(M, t_{k+1}\right)\right]$ is the range of $\xi(M)$ between $t_{k}$ and $t_{k+1}$, where $\xi\left(M, t_{k}\right)=\sum_{i=1}^{6} \xi_{i}\left(M, t_{k}\right)$, when strain energy is given to the material. It is defined as follow ( $M$ is omitted to simplify equations):

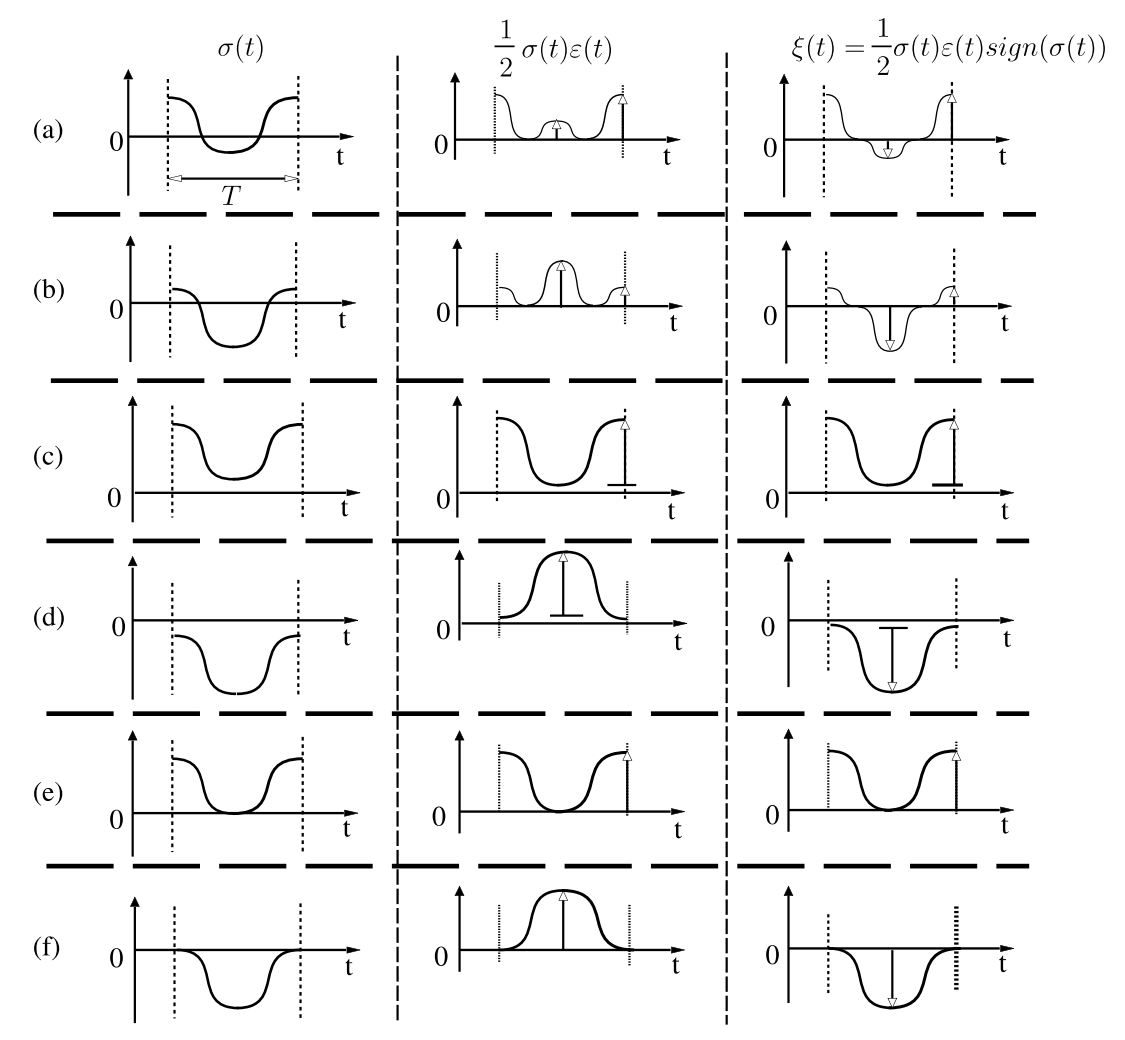

Fig. 1. Illustration of the potential strain energy density, $(1 / 2) \sigma(t) \xi(t)$, and the signed potential strain energy density, $\xi(t)$ for a uniaxial stress state $\sigma(t)$. 
- if $\xi\left(t_{k}\right)<\xi\left(t_{k+1}\right)<0$ or $\xi\left(t_{k}\right)>\xi\left(t_{k+1}\right)>0$, no strain work is given: $\Delta^{+}\left[\xi\left(t_{k}\right), \xi\left(t_{k}+1\right)\right]=0$, this is illustrated for instance by the transitions $t_{12} \rightarrow t_{13}$ and $t_{3} \rightarrow t_{4}$ in Fig. 7(c).

- if $0<\xi\left(t_{k}\right)<\xi\left(t_{k}+1\right)$ or $0>\xi\left(t_{k}\right)>\xi\left(t_{k}+1\right)$, the strain work given is: $\Delta^{+}\left[\xi\left(t_{k}\right), \xi\left(t_{k+1}\right)\right]=\left|\xi\left(t_{k+1}\right)-\xi\left(t_{k}\right)\right|$, see for instance the transitions $t_{4} \rightarrow t_{5}$ and $t_{15} \rightarrow t_{16}$ in Fig. 7(c).

- if $\operatorname{sign}\left(\xi\left(t_{k}\right)\right) \neq \operatorname{sign}\left(\xi\left(t_{k+1}\right)\right)$, the strain work given is: $\Delta^{+}\left[\xi\left(t_{k}\right), \xi\left(t_{k+1}\right)\right]=\left|\xi\left(t_{k+1}\right)\right|$, this is, for instance, the case of the transitions $t_{1} \rightarrow t_{2}$ and $t_{2} \rightarrow t_{3}$ in Fig. 7(c).

\subsection{Simplification algorithm}

The basic concept of the proposal is to erase the transitions between $t_{k}$ and $t_{k+1}$ in the stress history so that $\mathrm{Wg}\left(M, t_{k} \rightarrow t_{k+1}\right)<$ $\mathrm{Wg}^{*}(M)$, where $\mathrm{Wg}^{*}(M)$ is defined by Eq. (4). In first assumption, this threshold value is assumed to be independent from the mean stress. Nevertheless, a special case has to be considered, when the sign of $\xi(M)$ is changing during a transition (i.e. from tension to compression for a unixial stress state or vice-versa) as illustrated by Fig. 2. In such a case, it is assumed that the threshold $\mathrm{Wg}^{*}(M)$ is divided in two equal parts $\mathrm{Wg} *(M) / 2$.
This means that, at a point $M$ of the component, the strain work energy density given to the elementary volume of material around $M$ to initiate damage is assumed to be the same in tension and in compression: $\mathrm{Wg} *($ compression $)=$ $\mathrm{Wg} *($ tension $)=\mathrm{Wg} * / 2$. Thus, the conditions to eliminate a transition are:

- if $\operatorname{sign}(\xi(t k)) \neq \operatorname{sign}\left(\xi\left(t_{k+1}\right)\right): \mathrm{Wg}\left(M, t_{k} \rightarrow t_{k+1}\right)<\mathrm{Wg}^{*}(M) / 2$,

- if $\operatorname{sign}(\xi(t k))=\operatorname{sign}\left(\xi\left(t_{k+1}\right)\right): \mathrm{Wg}\left(M, t_{k} \rightarrow t_{k+1}\right)<\mathrm{Wg} *(M)$.

These conditions are illustrated in Fig. 2. A fully reversed stress cycle is damaging if $\mathrm{Wg}=\mathrm{Wg}$ (tension) $+\mathrm{Wg}$ (compression) $>\mathrm{Wg}^{*}$ as shown in Fig. 2(a). But this is different when there is a mean stress. In Fig. 2(b), the damaging strain work corresponds to the stress variation from $\left(-\sigma^{*}\right)$ to the minimum stress (compression): this work is $\left|\xi_{\min }\right|-W f^{*} / 2$. In Fig. 2(c), the damaging work is given to the material in tension from $\left(+\sigma^{*}\right)$ to the maximum stress: $\xi_{\max }-W f^{*} / 2$.

The global algorithm of the proposed technique is illustrated in Fig. 3. The results of this algorithm is a peak and valley time history of the stresses and strains with a number of points (i.e. extrema) lower than the original
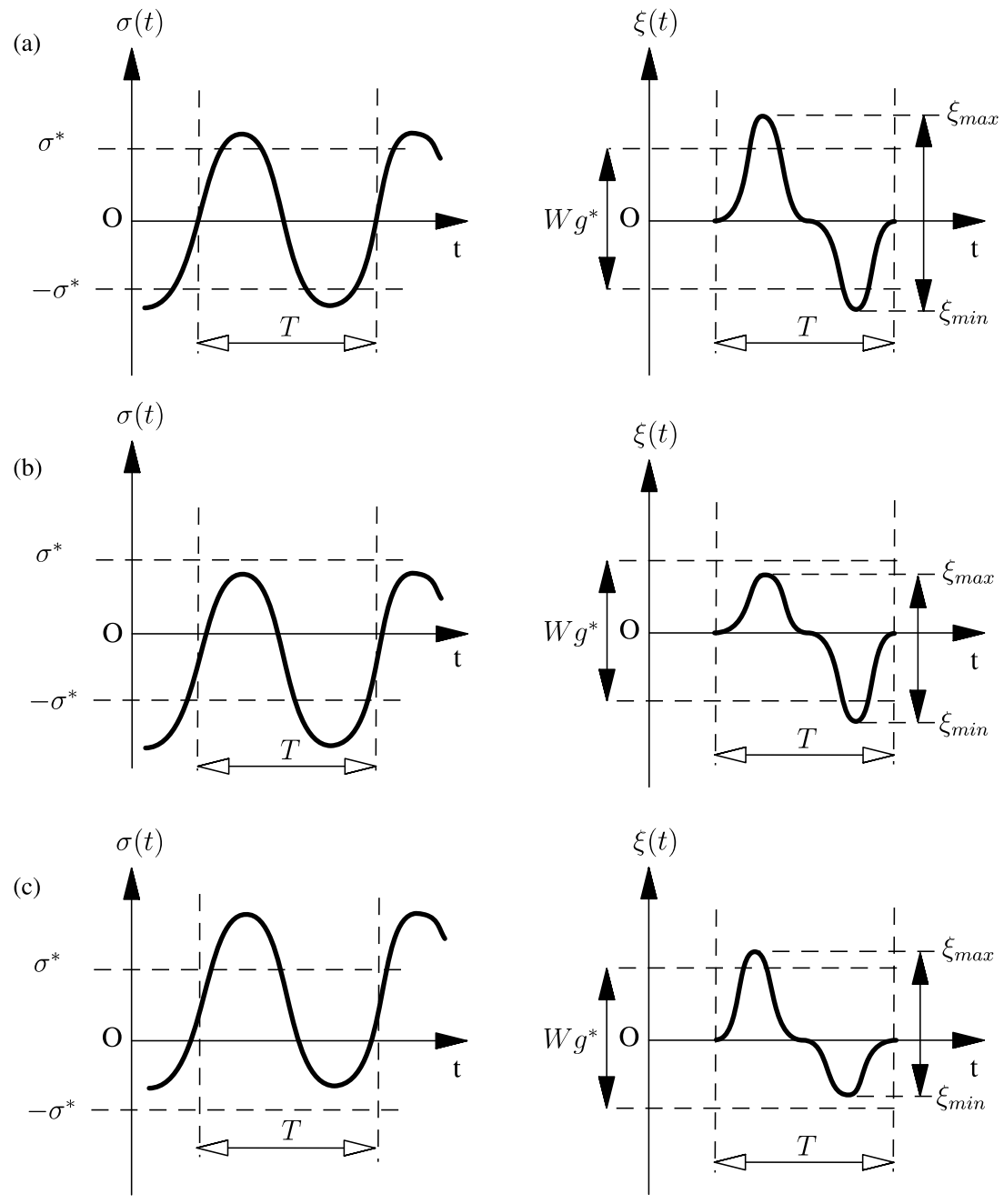

Fig. 2. Illustration of the assumption made for $\mathrm{Wg}^{*}$ when the sign of $\xi$ is changing. 


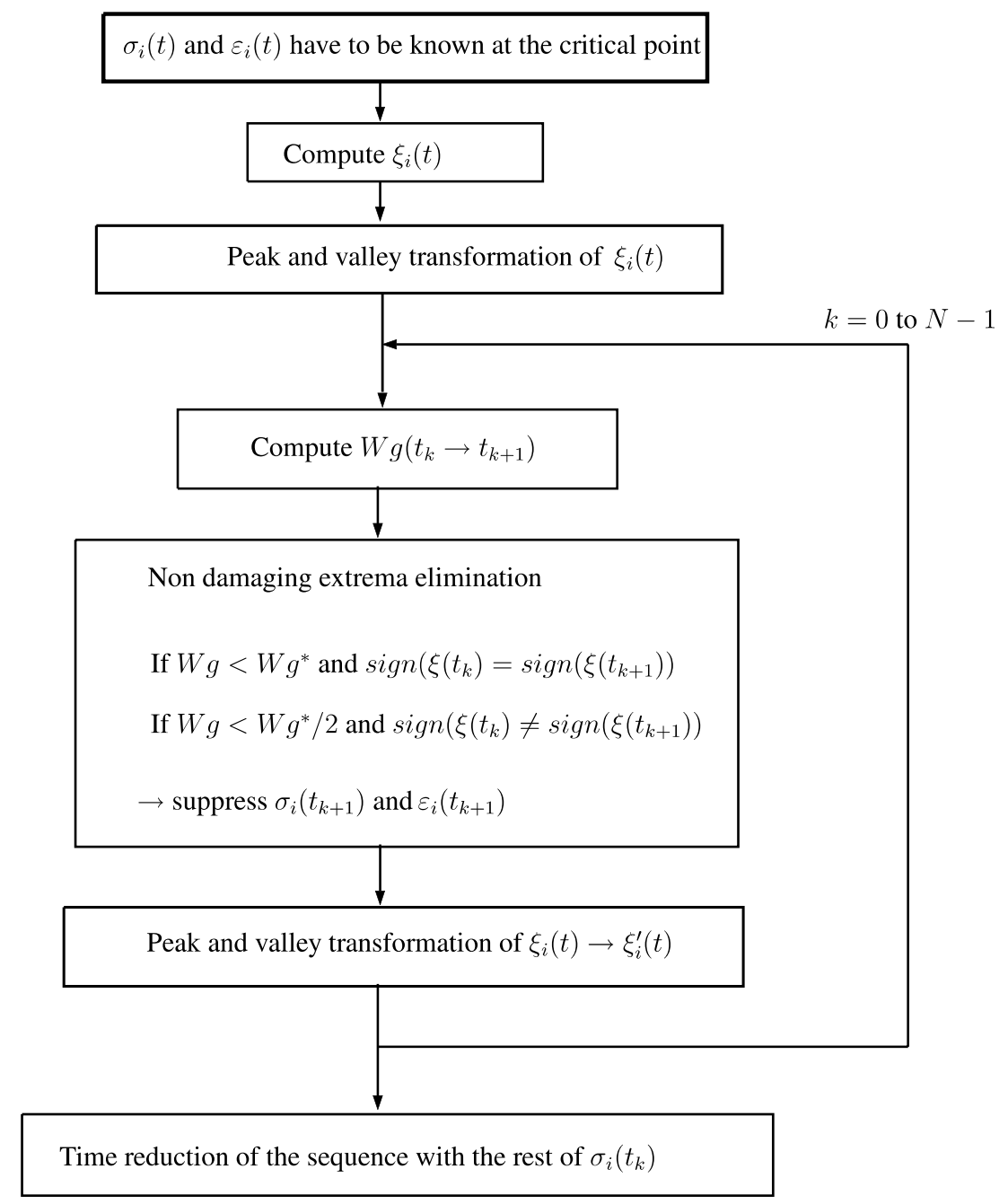

Fig. 3. Algorithm of the proposal for proportional multiaxial stress states ( $N$ is the number of extrema in the $\xi_{i}(t)$ time history).

sequence. A complete example of the proposal is given in Fig. 7 in Appendix A. The time interval between each peak and valley has then to be reduced at the smallest value in agreement with the bandwidth of the fatigue test rig. Indeed, the power spectral density of the signal which has to be reproduced on the component after reduction has to be in agreement with the bandwidth of the fatigue test rig to avoid a low pass filtering effect due to the servo-hydraulic and mechanical testing device.

\section{Experimental fatigue tests and discussion}

\subsection{Material and specimens}

All the experiments were carried out on round smooth specimens $\left(K t_{\text {bend }}=1.07\right.$ in bending, $K t_{\text {tor }}=1.04$ in torsion, diameter $12 \mathrm{~mm}$ ) made of quenched and tempered spheroidal graphite cast iron EN-GJS800-2. These specimens, illustrated in Fig. 4, are the same than those used in $[4,13]$. Details and

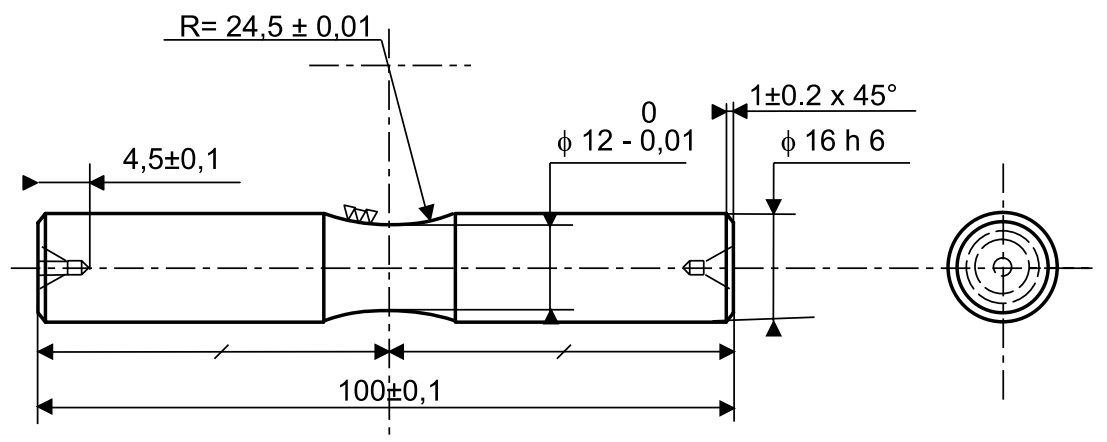

Fig. 4. Geometry of the smooth specimens $\left(K t_{\text {bend }}=1.07, K t_{\text {to }}=1.05\right)$. 

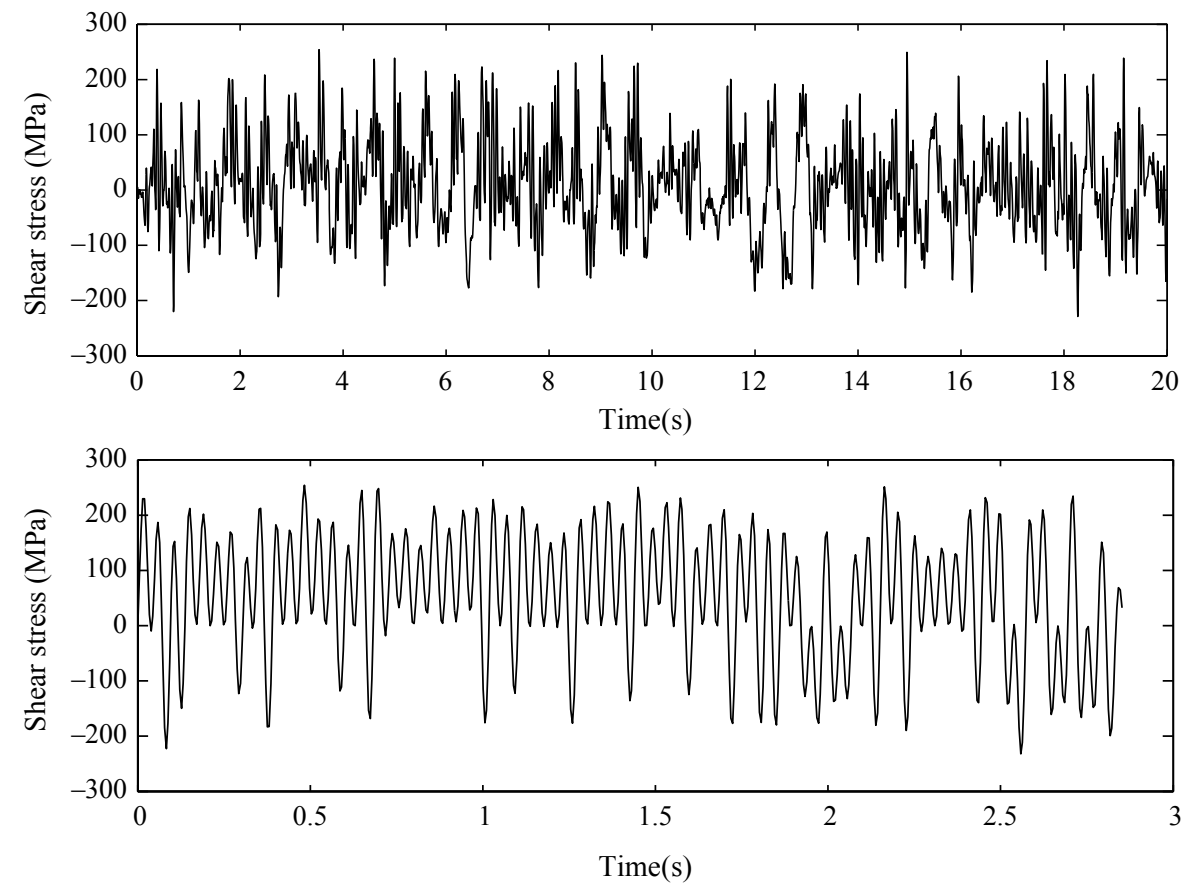

Fig. 5. Real time (top) and simplified (bottom) shear stress time history for torsion tests.

mechanical characteristics of the material are given in Refs $[4,13]$.

\subsection{Fatigue tests and validation}

The load controlled experiments were carried out on a closedloop servo-hydraulic multiaxial fatigue testing machine designed and made by ENSAM. [14]. This combined bending and torsion fatigue testing machine is able to servo-control in real time, not only the peaks and valleys of the bending and torsion moments, but their time evolution also [13]. The load sequences are repeated as long as the specimen stiffness decreases more than $10 \%$. With this condition, the size of the fatigue macrocrack detected is approximatively $2 \mathrm{~mm}$ in depth (under variable amplitude loadings) for the tested specimens (diameter of $12 \mathrm{~mm}$ ).

To check the proposal, experiments were carried out in four point plane bending, in torsion and in proportionally combined plane bending and torsion. The stress strain-time history is coming from a real loading sequence recorded by means of strain gauges stuck on a car suspension arm. A signal analysis of the total recorded sequence (34 s equivalent to a road of $200 \mathrm{~m}$ in length) shows that this signal is gaussian and stationary, with a bandwidth of $50 \mathrm{~Hz}$ [13]. The original sequences were applied to the specimens with a global mean value equal to zero. Nevertheless, a rainflow cycle counting algorithm applied on the shear stress time history shows that there are some cycles with a great mean value [13]. Fig. 5 illustrates the shear stress time history caused by the reference load sequence (original one before any simplification) during the torsion tests and the corresponding simplified sequence. The duration of the sequence is divided by seven.

Fatigue test results are indicated in Table 1 and illustrated in Fig. 6 for both test conditions in real time (reference) and with the simplified sequences. Eight specimens were tested for each real time load sequence and five under each simplified one. The dark marks represent the median number of sequences to crack initiation $N f_{0.50}$, the horizontal line around each mark represents the interval $\left[N f_{0.16}, N f_{0.84}\right]$. This interval was computed from experiments assuming that $N f$ is a log-normal random variable. The lives under the simplified sequences are in very good agreement with the real time lives.

Table 1

Fatigue test results under both original (i.e. as recorded before any simplification) and simplified sequences

\begin{tabular}{|c|c|c|c|c|c|c|}
\hline Signal & Nb. Spec. & Loading & $N f_{0.16}$ & $N f_{0.50}$ & $N f_{0.84}$ & $\begin{array}{l}\text { Mean test duration } \\
\text { (h) }\end{array}$ \\
\hline Original & 8 & Torsion & 12688 & 19020 & 28513 & 106 \\
\hline Simplified & 5 & Torsion & 13664 & 19190 & 26951 & 15 \\
\hline Original & 8 & Plane bending & 5989 & 11268 & 21270 & 63 \\
\hline Simplified & 5 & Plane bending & 13664 & 15192 & 16890 & 10 \\
\hline Original & 8 & Pl. bend. + tors. & 6269 & 16496 & 43406 & 91 \\
\hline Simplified & 5 & Pl. bend. + tors. & 10676 & 16816 & 26487 & 9 \\
\hline
\end{tabular}

Number of sequences to fatigue crack initiation with a probability of $0.5, N f_{0.50}$, and for the probability 0.16 and 0.84 ( $N f_{0.16}$ and $N f_{0.84}$, respectively). 

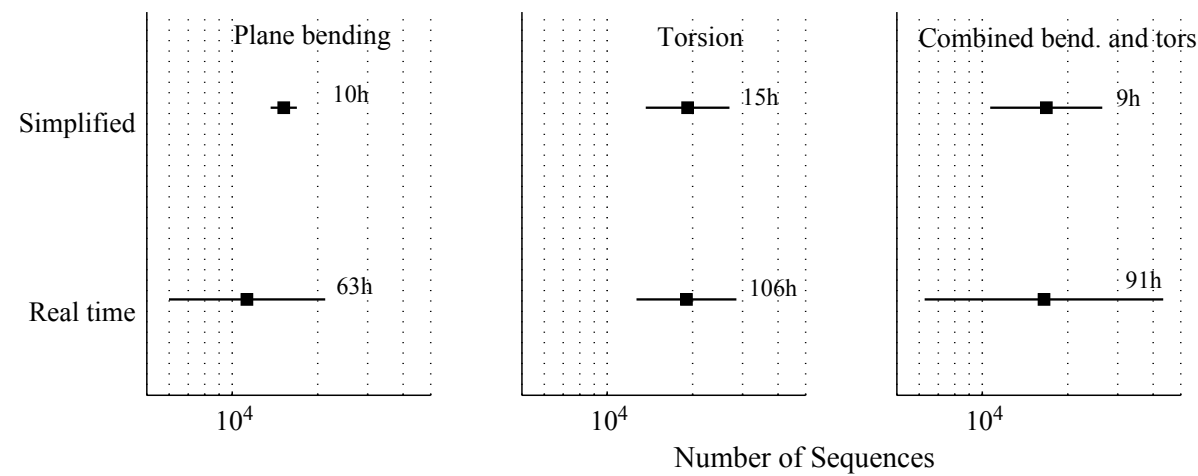

Fig. 6. Experimental number of sequences to crack initiation under real time (original) and simplified sequences on smooth specimens in EN-GJS800-2 cast iron ( $x \mathrm{~h}$ indicates the mean duration of a test in hours).

\subsection{Discussion}

Since, the threshold stress $\sigma^{*}$ has a physical significance [4] and its identification is easy from two endurance limit (see Eq. (2)), the simplification of any proportional stress-strain time history is simple without any empirical threshold stress level.
As illustrated in Fig. 6, the scatter of the fatigue life is larger under real time conditions than under simplified load sequences. This can be due to the small cycles suppressed from the reference sequence. They may participate a little to the damage in the material. In the proposed method, the threshold stress $\sigma^{*}$ and its corresponding energy threshold $\mathrm{Wg}^{*}$ is strict, this may be

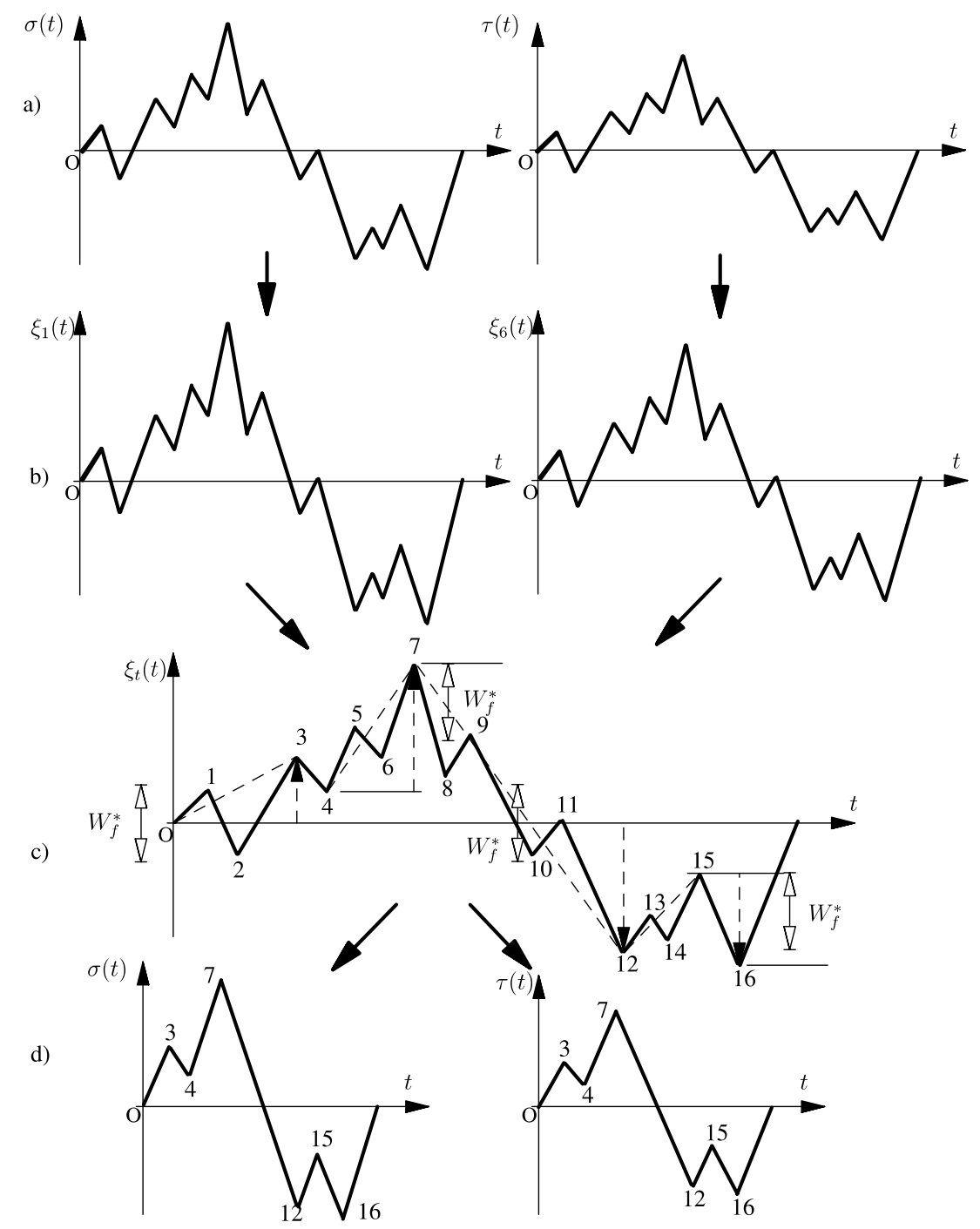

Fig. 7. Example of the proposal on a stress-strain time history for a combined bending and torsion loading. 


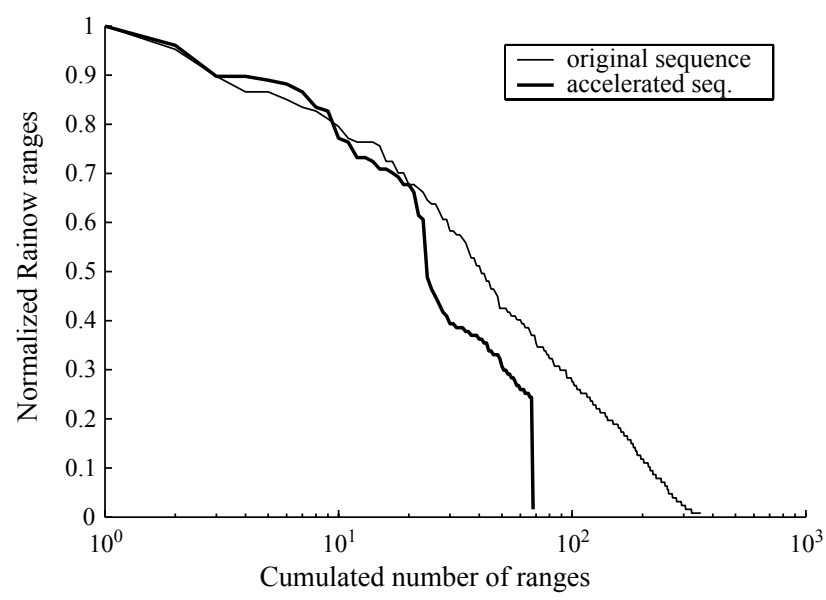

Fig. 8. Cumulated diagram of normalized rainflow stress ranges for the original and simplified sequence in torsion.

a strong hypothesis. The relative weight of 'stress cycles' (or stress transitions) is probably decreasing continuously together with the stress level below the conventional endurance limit. Nevertheless, the proposal discussed here is in very good agreement with experiments in real time. The time reduction factor of the simplified fatigue test is varying between 6 and 10 (Fig. 6) for our experiments. Of course, this time reduction is depending on the stress strain-time history. The reduction is all the more important because the stress strain history contains small fluctuations compared with the threshold stress $\sigma^{*}$ and its corresponding energy threshold $\mathrm{Wg}^{*}$. To illustrated this, let us consider a uniaxial variable amplitude tension test where all the cycles would have stress amplitudes below the threshold stress $\sigma^{*}$; in such a case the time reduction would be infinite, since the original signal would be non-damaging according to the proposal (it would not be necessary to run a fatigue test). On the contrary, if the original sequence is formed with cycles with stress amplitudes higher than $\sigma^{*}$, all the cycles are damaging, there would be no time reduction.

Even if the proposed technique is completely different from a Rainflow filtering, Fig. 8 illustrates the reduction of the number of cycles extracted (with the rainflow algorithm) from the simplified shear stress sequence in torsion. This figure shows that the 'small cycles' are not considered (if their normalized stress amplitude is lower than approximatively 0.25 . Furthermore, Figs. 5 and 8 show that the proposed technique do not magnify the stress range. The simplified and original sequences have the same maximum and minimum. This means that the material is always loaded in the same local plasticity conditions if any. This is in agreement with the experimental observations done by Grubisic [3] and with the Sonsino's recommendations [1].

The strain work energy density given to an elementary volume of the material $\mathrm{Wg}$ is a mean stress dependent parameter as detailed in Refs [8,5] and illustrated in Fig. 9. In this figure, the two hatched areas ( $\mathrm{A}^{\prime} \mathrm{B}^{\prime} \mathrm{O}+\mathrm{OAB}$ and $\mathrm{CDEF}$ ) correspond to the strain work energy density given to the material between the two transitions, respectively $\left(t_{0} \rightarrow t_{1}+t_{1^{\prime}} \rightarrow t_{2}\right)$ and $t_{5} \rightarrow t_{6}$. This means that without any mean stress correction, e.g. the ones from Goodmann or Gerber, the proposed simplification method is able to consider as damaging a small stress fluctuation with a high normal mean stress and to consider as non damaging (i.e. to erase this fluctuation from the original sequence) the same stress fluctuation with a low mean stress or zero mean stress. In Fig. 9, $\Delta \sigma_{12}$ is below the stress range of a cycle with the stress amplitude $\sigma^{*}$, the transitions $t_{0} \rightarrow t_{1}$ and $t_{1^{\prime}} \rightarrow t_{2}$ are non damaging. Even if $\Delta \sigma_{56}<\Delta \sigma_{12}$ during the transition $t_{5} \rightarrow t_{6}$ the strain work energy density given to the material, $\mathrm{Wg}\left(t_{5} \rightarrow t_{6}\right)$, is higher than $\mathrm{Wg}\left(t_{0} \rightarrow\right.$ $\left.t_{1}\right)+\mathrm{Wg}\left(t_{1^{\prime}} \rightarrow t_{2}\right)$ and $\mathrm{Wg}^{*}$ (see hatched area CDEF in Fig. 9 which is very larger than area $\left.\mathrm{A}^{\prime} \mathrm{B}^{\prime} \mathrm{OAB}\right)$.

The drawback of this proposal is to consider positive and negative mean stresses in the same way. But this leads to a conservative (safety) simplification of the original sequence, because a negative normal mean stress is known as increasing the fatigue live. For shear stresses, Banvillet et al. [8,5] showed that the use of the strain work energy density given to an elementary volume of the material leads to a multiaxial fatigue criterion with a very low mean shear stress sensitivity if the maximum shear stress remains below approximatively $0.8 \tau_{y}$, where $\tau_{y}$ is the shear yield stress of the material. This is in agreement with the literature $[15,16]$.

\section{Conclusion and prospects}

A technique to reduce the duration of multiaxial fatigue tests under variable amplitude proportional loadings was proposed and validated by experiments. This leads to the reduction of the testing time by a factor between 6 and 10 for the real stress-strain sequences (coming from a car suspension arm) used in our experiments. The threshold stress $\sigma^{*}$, and its corresponding strain work energy density given to the material $\mathrm{Wg}^{*}$, used in this technique are representative of the threshold below which microcarck are arrested in the material [4]. Two fully reversed

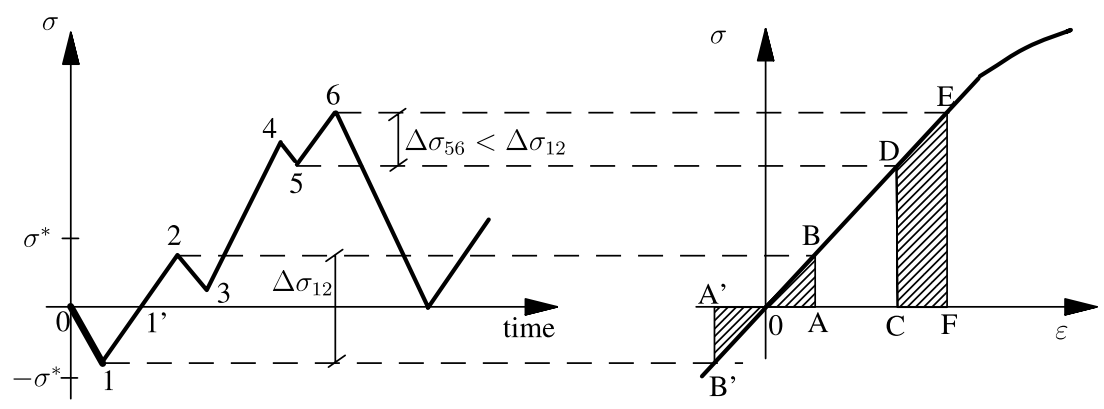

Fig. 9. Illustration of the mean stress sensitivity of $\mathrm{Wg}$ (example of a uniaxial stress state). 
endurance limits on smooth specimens are needed to identify the threshold parameter $\mathrm{Wg}^{*}$ of the proposal (tension and rotating bending); this is enough to simplify uniaxial variable amplitude sequences. A third fully reversed endurance limit on smooth specimens (torsion) is needed to identify the $\beta$ parameter used to take into account the material sensitivity to the triaxiality of stresses. Under the simplified sequence, the material is loaded in the same stress-strain range as under the real time sequence (reference). The proposed method is sensitive to the normal mean stress but is not mean shear stress dependent if the maximum shear stress is below the yield shear stress of the material. Additional experiments have to be done on longer stress-strain histories, on various materials and load sequences to confirm the efficiency of the proposal. Nevertheless, the proposed technique is very promissing. An evolution of this methodology for nonproportional multiaxial stress states is developed.

\section{Appendix A. Simplification example of a combined bending and torsion history}

In Fig. 7, the proposed technique is illustrated for a stress history corresponding to a proportionally combined bending and torsion loadings. The strain history can be easily deduced from the stress history because the material was loaded in elasticity at the macroscopic scale. To simplify the understanding of the proposal, the threshold strain work density $\mathrm{Wg}^{*}$ is assumed to be the same for each transition $t_{k} \rightarrow t_{k+1}$; in fact this threshold is depending on the triaxiality degree of stresses, that is why $\mathrm{Wg}^{*}$ has to be computed for each transition according to Eqs. (3) and (4).

Since, $\sigma(t)=\sigma_{1}(t)$ and $\tau(t)=\sigma_{6}(t)$ are synchronous, the time evolution of these stresses is transformed in peaks and valleys (Fig. 7(a)). Then $\xi_{1}(t)$ and $\xi_{6}(t)$ are computed (Fig. 7(b)). The strain energy transitions due to each stress component are synchronous, thus the sum of the strain work due to $\sigma$ and $\tau$, are equal to the range of the signed strain energy density $\xi_{t}(t)=$ $\xi_{1}(t)+\xi_{6}(t)$ (Fig. 7(c)). By comparing the $\xi_{t}$ range between a peak and a valley with the threshold strain work density $\mathrm{Wg}^{*}\left(C_{\mathrm{i}}\right)$ (see flow chart Fig. 3), the non-damaging transitions can be identified and erased from the original signal. The simplified signal is illustrated in Fig. 7(d) as explained in the following.

Step 1 The first time of the stress history creating damage according to the proposal is so that: $\left|\xi_{t}\left(t_{k}\right)\right|>(0.5 \times$ $\left.\mathrm{Wg}^{*}\right)$. In Fig. 7(c), $\xi_{t}\left(t_{1}\right)$ and $\xi_{t}\left(t_{2}\right)$ are lower than $(1 / 2) W_{f}^{*}$, thus $\sigma\left(t_{1}\right)$ and $\sigma\left(t_{2}\right)$ (and so $\xi_{t}\left(t_{1}\right)$ and $\xi_{t}\left(t_{2}\right)$ ) can be erased from the history.

The first damaging strain work is the difference: $\xi_{t}\left(t_{3}\right)>\left((1 / 2) \times W_{f}^{*}\right)$.

Step 2 Between $t_{3}$ and $t_{4}$, no strain work is given to the material because $\xi_{t}\left(t_{4}\right)-\xi_{t}\left(t_{3}\right)<0$, go to the next transition.

Step 3 The strain work density given between $t_{4}$ and $t_{5}$ is $\xi_{t}\left(t_{5}\right)-\xi_{t}\left(t_{4}\right)<W_{f}^{*}$. So, $\sigma_{i}\left(t_{5}\right)\left(\xi_{t}\left(t_{5}\right)\right.$ also $)$ is erased in the stress history. Then the peak and valley filtering of $\xi_{i}^{\prime}(t)$ between $t_{0}$ and $t_{7}$ leads to erase $\sigma_{\mathrm{i}}\left(t_{6}\right)$ and $\xi_{t}\left(t_{6}\right)$. Step 4 The strain work density given between $t_{4}$ and $t_{7}$, $\xi_{t}\left(t_{7}\right)-\xi_{t}\left(t_{4}\right)$ is higher than $W_{f}^{*}$, that is why this is considered as a damaging transition.

Step 5 The strain work density from $t_{7}$ to $t_{8}$ is negative (the material is unloaded), go to the next extremum.

Step 6 The strain work density given from $t_{8}$ to $t_{9}$ is $\xi_{t}\left(t_{9}\right)-\xi_{t}\left(t_{8}\right)<W_{f}^{*} . \sigma\left(t_{9}\right)\left(\xi_{t}\left(t_{9}\right)\right)$ also) is erased from the stress history. Then during the peak and valley filtering of $\xi_{t}(t)$ between $\left(t_{0}\right)$ and $\left(t_{10}\right), \sigma_{i}\left(t_{8}\right)$ and $\xi_{t}\left(t_{8}\right)$ are erased.

Step 7 The strain work density from $\xi_{t}\left(t_{7}\right)$ to zero is negative (the material is unloaded from $\xi_{t}\left(t_{7}\right)$ to zero). From zero to $\left(t_{10}\right)$ the strain work density given in compression is $\left|\xi_{t}\left(t_{10}\right)\right|$. But $\left|\xi_{t}\left(t_{10}\right)\right|<\left(0.5 \times W_{f}^{*}\right)$ so $\sigma_{i}\left(t_{10}\right)$ (and $\xi_{t}\left(t_{10}\right)$ also) have to be erased from the stress history (Fig. 7(c)). $\sigma_{i}\left(t_{11}\right)$ and $\xi_{t}\left(t_{11}\right)$ are suppressed with the peak and valley filtering of $\xi_{t}^{\prime}(t)$ between $\left(t_{0}\right)$ and $\left(t_{12}\right)$.

Step 8 The strain work density from $\left(t_{7}\right)$ to $\left(t_{12}\right)$ is negative from $\xi_{t}\left(t_{7}\right)$ to zero (unloaded state) then from zero to $t_{12}$ the strain work energy density is given in compression: $\left|\xi_{t}\left(t_{12}\right)\right|$. This work is damaging according to the proposal because: $\left|\xi_{t}\left(t_{12}\right)\right|>(1 / 2) W_{f}^{*}$. Go to the next transition.

Step 9 From $t_{12}$ to $t_{13}$ the strain work is negative (given back); go to the next transition. The strain work density given in compression from $t_{13}$ to $t_{14}$ is lower than $W_{f}^{*}, t_{14}$ is erased. Then the extremum at $t_{13}$ is erased also with the peak and valley filtering of $\xi_{t}$ between $t_{0}$ and $t_{14}$. Go to the next transition.

Step 10 The strain work given in compression from $t_{15}$ to $t_{16}$ is: $\left|\xi_{t}\left(t_{16}\right)-\xi_{t}\left(t_{15}\right)\right|>W_{f}^{*}$. This is a damaging work. Go to the next transition.

Fig. 7(d) shows the time evolution of the normal $\sigma_{1}(t)=\sigma(t)$ and the shear $\sigma_{6}(t)=\tau(t)$ stresses after the proposed simplification technique, with the same time interval between all the extrema (peaks and valleys). This delay between peak and valley has to be defined in agreement with the bandwidth of the fatigue test stand. The duration of the simplified sequence is shortest than the original one.

Nota: If the stress history is not starting from $0\left(\sigma\left(t_{0}\right) \neq 0\right)$, or does not cross zero during the sequence, the algorithm of the proposal is exactly the same: the first point of the stress history is kept.

\section{References}

[1] Sonsino CM. Versuchszeitverkürzung in der Betriebsfestigkeitsprüfung. MP Materialprüfung 2003;4:133-44.

[2] Gründer B, Speckert M, Pompetzki M. Design of durability sequences based on rainflow matrix optimization. SAE Tech. Paper Series 1998; (980690):1-8.

[3] Grubisic V. Determination of load spectra for design and testing. Int J Vehicle Des 1994;15(1/2):8-26. 
[4] Palin-Luc T, Lasserre S, Bérard Y. Experimental investigation on the significance of the conventional endurance limit of a spheroidal graphite cast iron. Fatigue Fract Eng Mater Struct 1998;21(3):192-200.

[5] Banvillet A, Palin-Luc T, Lasserre S. A volumetric energy based high cycle multiaxial fatigue criterion. Int J Fatigue 2003;25:755-69.

[6] Banvillet A, Palin-Luc T, Lasserre S, Vittori J-F. Energy based high cycle multiaxial fatigue criterion depending on stress-strain distribution. In: Blom AF, editor. 8th IFC, Fatigue 2002, Stockholm, Sweden. EMAS, 2002. p. 283-90.

[7] Palin-Luc T, Lasserre S. An energy based criterion for high cycle multiaxial fatigue. Eur J Mech, A/Solids 1998;17(2):237-51.

[8] Banvillet A. Prévision de durée de vie en fatigue multiaxiale sous chargements réels: vers des essais accélérés. PhD Thesis. ENSAM CER de Bordeaux, France; 2001. 266 p.

[9] Palin-Luc T, Banvillet A, Lasserre S, Vittori J.-F. A technique to reduce the duration of multiaxial fatigue tests under service loadings. In: Seventh international conference on biaxial multiaxial fatigue fracture, Berlin, 28 June-1st July 2004. ESIS; 2004. p. 421-426.

[10] Lemaitre J, Chaboche J-L. Mécanique des matériaux solides. Paris: Bordas; 1988. $544 \mathrm{p}$.
[11] Palin-Luc T, Lasserre S, Bérard J.-Y. Une limite de non propagation des microfissures inférieure à la limite d'endurance conventionnelle sur une fonte GS. In: 14ème Congrès Français de Mécanique, Toulouse, France, 30 Août-3 Sept 1999. AUM. 6 pages on CD-Rom.

[12] Delahay T. Développement d'une méthode de calcul probabiliste en fatigue multiaxiale prenant en compte les gradients de contraintes. PhD Thesis. ENSAM CER de Bordeaux, France; 2004.

[13] Banvillet A, Palin-Luc T, Vittori J-F. Fatigue life of a SG cast iron under real loading spectra: effect of the correlation factor between bending and torsion. J ASTM Int 2004;1(8) [13 pages, Paper ID19040].

[14] Palin-Luc T, Lasserre S. Multiaxial fatigue testing machine under variable amplitude loading of bending and torsion. In: Silva Gomes JF, et al, editors. Recent advances in experimental mechanics. Rotterdam: A.A. Balkema; 1994.

[15] Sines G. Behavior of metals under complex static and alternating stresses. In: Dolan TJ, Sines G, Waisman JL, editors. Metal fatigue. New York: McGraw-Hill; 1959. p. 145-69.

[16] Smith JO. The effects of range of stress on fatigue strength of metals. Eng Exp Station, Bull 334 1942;39(26). 52 p. 